\title{
Development of hardware system using temperature and vibration maintenance models integration concepts for conventional machines monitoring: a case study
}

\author{
Michael Kanisuru Adeyeri ${ }^{1} \cdot$ Khumbulani Mpofu' $^{1} \cdot$ Buliaminu Kareem $^{2}$
}

Received: 3 October 2014/ Accepted: 25 November 2015/Published online: 15 December 2015

(C) The Author(s) 2015. This article is published with open access at Springerlink.com

\begin{abstract}
This article describes the integration of temperature and vibration models for maintenance monitoring of conventional machinery parts in which their optimal and best functionalities are affected by abnormal changes in temperature and vibration values thereby resulting in machine failures, machines breakdown, poor quality of products, inability to meeting customers' demand, poor inventory control and just to mention a few. The work entails the use of temperature and vibration sensors as monitoring probes programmed in microcontroller using $\mathrm{C}$ language. The developed hardware consists of vibration sensor of ADXL345, temperature sensor of AD594/595 of type $\mathrm{K}$ thermocouple, microcontroller, graphic liquid crystal display, real time clock, etc. The hardware is divided into two: one is based at the workstation (majorly meant to monitor machines behaviour) and the other at the base station (meant to receive transmission of machines information sent from the workstation), working cooperatively for effective functionalities. The resulting hardware built was calibrated, tested using model verification and validated through principles pivoted on least square and regression analysis approach using data read from the gear boxes of extruding and cutting machines used for
\end{abstract}

Michael Kanisuru Adeyeri

adeyerimichaeltut@gmail.com; adeyerimk@tut.ac.za

Khumbulani Mpofu

mpofuk@tut.ac.za

Buliaminu Kareem

bkareem@futa.edu.ng

1 Department of Industrial Engineering, Tshwane University of Technology, Pretoria, South Africa

2 Department of Mechanical Engineering, The Federal University of Technology, Akure, Nigeria polyethylene bag production. The results got therein confirmed related correlation existing between time, vibration and temperature, which are reflections of effective formulation of the developed concept.

Keywords Maintenance model - Agent hardware system · Conventional machines · Machine conditions monitoring

\section{Introduction}

The manufacturing world is fast evolving, revolving and transforming to E-manufacturing especially in the developed world where technological advancement is changing rapidly every second which calls for the introduction and use of sophisticated, knowledge-based and highly intelligent machines for industrial uses. The maintenance of these machines which are purely done on e-maintenance platform as corroborated by Iung et al. (2009) are assisted by the use of inbuilt mechanism through artificial intelligence, expert system, neural network, agents and multi agents software that tends to automatically effect changes, carries out repairs and suggest possible means to avert the intending failures and total breakdown. With this dramatic change, consideration is no more given to the developing and underdeveloped countries as well as the less privileged (those who are into production and manufacturing activities at small scale level) who due to high cost could not adopt the use of these hybrid machines. This category of manufacturers has no option than to continue using the conventional machines at their reach and maintain them using the customary maintenance culture.

It is worth noting at this juncture to define what conventional machines are. According to Adeyeri et al. (2012), 
conventional machines are "machines which are operated manually. These machines are controlled by cams, gears, levers, or screws. Examples of these machines are Lathe, grinding machine, flaking machine, extruding machine and just to mention a few. They indeed needed special attention to safe guard or vouch safe for their functionality and optimal performance as compared to the non-conventional machines which are controlled automatically by integrated computer". In view of this, there should be a platform that bridges the gap between the rich manufacturing industries and the less privileged in the maintenance world or a platform that provides a face lift for the customary approach for maintenance practices. The customary maintenance technique is breakdown maintenance (which is also called unplanned maintenance, or run-to-failure maintenance), takes place only at breakdowns. Therefore this article gives an attempted concept of using an embedded approach in embedding sensors (agent hardware) for monitoring machinery conditions from the perspective view of vibration and temperature effects on machines performance.

The rest of this paper is structured as follows. "Literature review" section offers a brief review of the research in the area of maintenance and sensors description. "Methodology" section outlines the methods involved in developing the hardware components. The validation and verification of the development system are enclosed in "Results and discussion" section. Finally, last section summarizes conclusions of this work and outline guidelines for possible future work.

\section{Literature review}

Many researchers have written extensively on maintenance from various dimensions of types, framework, concepts and simulation to modelling theory. The works of Jardine et al. (1999), Koc and Lee (2001), Tao et al. (2003), Lee and Scott (2006), Lu et al. (2007), Mahantesh et al. (2008), Derigent et al. (2009) and Ahmad et al. (2011) were focused on maintenance types be it condition based, preventive and opportunistic. Some work results on maintenance plan, policies, strategies, review and framework had been showcased by Ucar and Qiu (2005), Tsang (2002), Albino et al. (1992), Yuan and Chaing (2000), Hausladen and Bechheim (2004), Dufuaa et al. (2001), Levrat et al. (2008), Iung et al. (2009), Muller et al. (2008) and Peng et al. 2010).

Some research outputs of Albino et al. (1992), Marquez and Herguedes (2002), Marquez et al. (2003), Zineb and Chadi (2001) and Ashraf (2004) are on maintenance models development for evaluation and optimal throughput. Results output through the application of simulation integration, artificial intelligence, neural network, genetic algorithm and knowledge-based expert into solving maintenance problems are already published by Dufuaa et al. (2001), Zineb and Chadi (2001), Andijani and Dufuaa (2002), Greasly (2005), Oladokun et al. (2006), Mahantesh et al. (2008), Voisin et al. (2010), Babaei et al. (2011) and Jasper et al. (2011).

Of recent times, in early 2000, the e-maintenance paradigm emerged. Technological development revealed that e-maintenance platform utilizes internet networking, intranetting and Extra-netting based on web technology, sensors application, wireless communications and mobile accessories (Iung and Marquez (2006) and Iung et al. (2009)). With this emerging technology, the concept of this work is therefore hinged on the application of sensors technology in assisting in the monitoring of machines behaviour from the view of vibration and temperature effects.

Lee et al. (2006) discussed that multiple degradation indicators built on sensor signals are the most potent tools needed for the real-time condition monitoring as potential failures could be attributed to many correlated degradation processes. It is in view of this that the present concept of hardware development is initiated. It is on the principle of embedded system.

Embedded systems are electronic systems that are intelligent enough to operate on their own without receiving operating commands from an external source. They are standalone systems which carry out their functions automatically with little supervision and operation. Examples of these systems are Global System for Mobile communication (GSM) handsets, calculators, microwave ovens, digital scrolling display, cameras, mouse, security alarm system, etc. At the centre of any embedded system is microcontroller. The remaining parts of this section are for the literature support of the core components for the proposed hardware (microcontroller, vibration and temperature sensors).

\section{Microcontrollers}

A microcontroller is a single chip, self-contained computer which incorporates all the basic components of a personal computer on a much smaller scale. Functionally, it is a programmable single chip which controls a process or a system. Microcontrollers are typically used as embedded controllers where they control part of a larger system such as an appliance, automobile, scientific instrument or a computer peripheral. Physically, a microcontroller is an integrated circuit with pins along each side which are used for power, ground, oscillator, input/output ports, interrupt request signals, reset and control.

There are various manufacturers of microcontrollers like Microchip (PIC series), Atmel (AVR series), Actel, 
Motorola (MPC series), Maxim integrated products, Texas instruments, Sharp (ARM series), Panasonic, etc. The microcontroller unit can be programmed in any language ranging from Assembly language to Basic, C, Pascal, as long as a compiler exists to convert the code to its machine equivalent (Muhammad et al. 2011).

\section{Vibration and temperature sensors}

The ADXL345 is a small, thin, low power, three-axis accelerometer with high resolution (13-bit) measurement at up to $\pm 16 \mathrm{~g}$. Digital output data are formatted as 16-bit twos complement and is accessible through either a SPI (3or 4-wire) or I2C digital interface. The ADXL345 is well suited for mobile device applications. It measures the static acceleration of gravity in tilt-sensing applications, as well as dynamic acceleration resulting from motion or shock. Its high resolution (4 mg/LSB) enables measurement of inclination changes $<1.0^{\circ}$ (OTW 2009). The ACCEL Board is the vibration sensor board made by Microelectronika, it is built around ADXL345, and the means of communication with the microcontroller is through the Serial Peripheral Interface (SPI). The board can measure vibration in three axes, with a resolution of $16 \mathrm{~g}$ (Atmel 2010).

Temperature measurement can be accomplished using several types of sensing mechanisms. Temperature measurement systems generally consist of a sensor, a transmitter, an external power supply (for some types of systems), and the wiring that connects these components. The temperature measurement sensors most commonly used in engineering applications are thermocouples, Resistance Temperature Detectors (RTDs), and infrared (IR) thermometers.

For simplicity, reliability, and relatively low cost, thermocouples are widely used. They are self-powered, eliminating the need for a separate power supply to the sensor. Thermocouples are durable when they are appropriately chosen for a given application. Thermocouples also can be used in high-temperature applications, such as incinerators (Grieb 1992).
Fig. 1 Hardware architecture of the designed concept

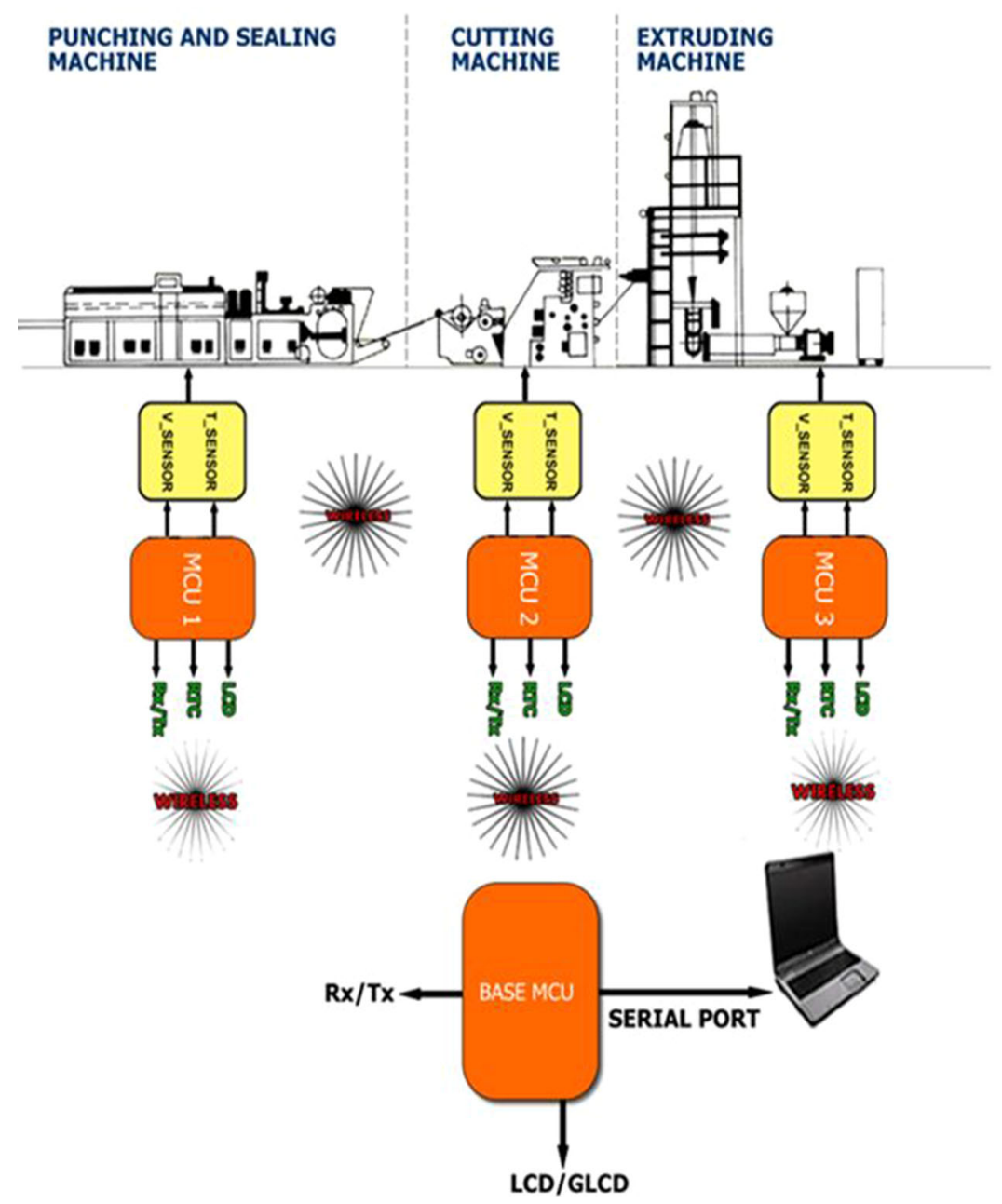

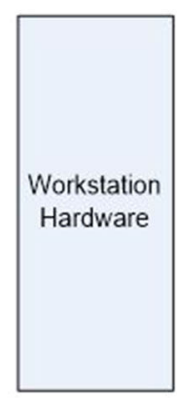

Base Station Hardware 


\section{Methodology}

The description of the methods behind this concept of maintenance monitoring shall be viewed under monitoring concept formulation, model formulation for vibration and temperature, algorithm formulation, materials needed for the hardware developed and its circuitry and calibration of the developed hardware.

\section{Hardware development for maintenance monitoring concept}

The block diagram representing the hardware concept and design for the condition monitoring is as shown in Fig. 1. As depicted, the embedded design consists of a base station embedded system connected directly to a PC and remote machine monitoring systems known as the substation or work station connected directly to the machines which can be produced in the number of machines in the industrial plant of interest.

It is worth noting that only the workstation hardware would be discussed fully in this research article.

\section{Materials for hardware development}

The tools and equipment needed for the hardware design and its implementation are as listed:

1. Computer hardware: (Vibration Transducer (ADXL345, AD595, type K thermocouple), AVR Microcontroller (Atmega16; Atmega32); Real Time clock (RTC); Liquid Crystal Display (LCD), MJ MRF24J40MA (2.4 GHz zigbee) transceiver, transformer, capacitor, resistors, MiKroC board platform, and Vero board.

2. Computer software: Microsoft visual studio, C\# and C language

3. Auxiliary tools: soldering lead, soldering iron, and USB.

\section{Model formulation}

Maintenance based model is formulated from the view of vibrational and temperature effect on machinery.

\section{Temperature-based maintenance model}

Adeyeri et al. (2012) assumed that if $T_{i}$ is the initial temperature value, and $T_{o}$ defined as the measured temperature before the predicted value of temperature at next planned time of measurement or reading, then the temperature deteriorating factor, $U_{T}$ is expressed as
$U_{T}=\frac{T_{i}-T_{o}}{T_{m}^{c}}$

where $T_{m}^{c}$ is critical temperature limit level.

Therefore, $T_{i}^{t_{a}}$, which is the predicted value of temperature at next planned time of measurement or reading taken, would be

$T_{i}^{t_{a}}=\left[T_{i}^{o}+T_{i}^{o} U_{T}\right]_{b}^{t_{n}}$

Simplifying Eq. (2) gives

$T_{i}^{t_{a}}=T_{i}^{o}\left[1+U_{T}\right]_{b}^{t_{n}}$

where $t_{n}$ is the periodic time numbering of readings and $b$ is a function of speed, environmental condition and product demand.

Therefore, if $T_{i}^{t_{a}} \geq T_{m}^{c}$, then maintenance is required, otherwise do not.

\section{Vibration-based maintenance model}

Dynamic components of machinery do give rise to one form of vibration or another. This vibration generated by its dynamic components is a potent parameter for condition monitoring. Condition monitoring based on vibration measurement and analysis can be carried out either on-load or off-load.

When dealing with Vibration-Based Maintenance (VBM), the condition of significant parts cannot be assessed effectively, i.e. with high certainty, without considering both probabilistic and deterministic aspects of the degradation process. Modelling the time for maintenance action and predicting the value of the vibration level when damage of a significant component is detected are examples of the probabilistic part. However, issues related to machine function, failure analysis and diagnostics are examples of the deterministic part.

Alsyouf (2004) formulated a sub model for predicting vibration level during the next period and until the next measuring moment as stated in Eq. (4). The equation formulated assumed that $V$ be the dependent variable representing the predicted value of the vibration level and that $V$ is a function of three independent variables $\left(V_{i}, Z, t\right)$ and three parameters $(a, b, c)$, for $i=1,2 \ldots n$, and $i$ is the number of measuring opportunities.

$V_{i+1}=\left[V_{i}+a e^{-\left(b_{i} t_{i+1} z_{i}^{c_{i}}\right)}\right]_{k}$.

where $V_{i+1}$ is the predicted value of the vibration level at the next planned measuring time. $t_{i+1}$ the elapsed time since the damage is initiated and its development is detected. $V_{i}$ the current vibration level value and $Z_{i}$ the deterioration factor, i.e. the function of the current and anticipated future load and previous deterioration rate. 
Fig. 2 Flowchart of condition based maintenance monitoring

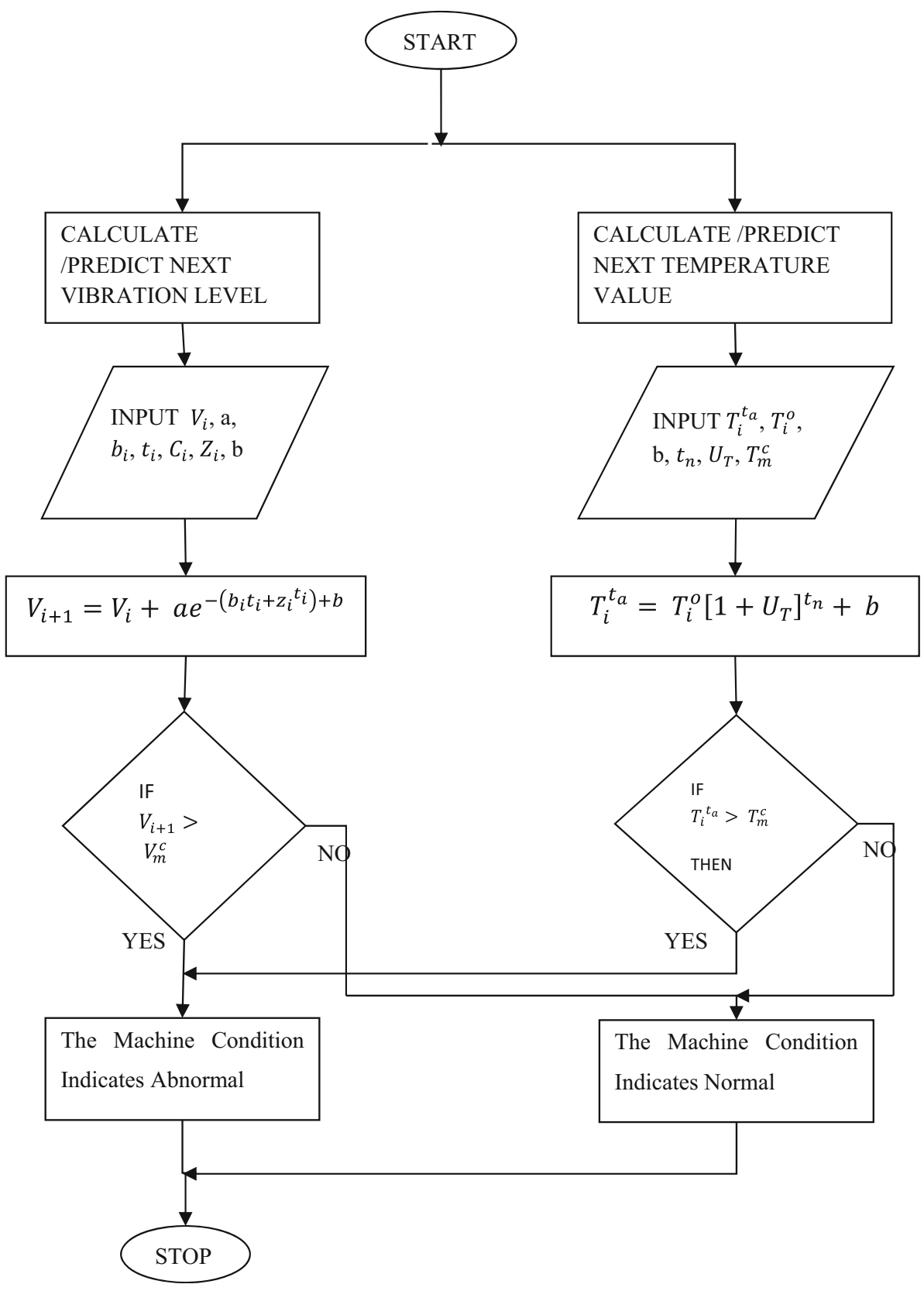

$Z_{i}=\left|\frac{V_{i}-V_{\mathrm{O}}}{V_{\mathrm{C}}}\right|$

where $V_{c}$ is the critical vibration level which is to be supplied by the manufacturer, $V_{\mathrm{o}}$ is the measured vibration before $V_{i+1}, a$ the gradient (slope) by which the value of the vibration level varied since it started to deviate from its normal state $\left(V_{\mathrm{o}}\right)$ due to initiation of damage until detecting it at $V_{p}, b_{i}$ and $c_{i}$ are on-linear model's constants, $K$ is a function of loading, speed of machine, environmental condition, and $E_{i}$ the model error, which is assumed to be identical, independent and normally distributed with zero mean and constant variance, $N(0, \sigma)$.

When $V_{i+1} \geq V_{\mathrm{c}}$ then maintenance is required, otherwise do not.

Mechanical vibrations a characterised in severity by one and all of these three basic parameters, viz a viz: displacement, velocity or acceleration. Velocity which is best suited for intermediate frequency range has found to give the best indication of severity over the wildest range of frequencies and hence has the wildest application in condition monitoring. 


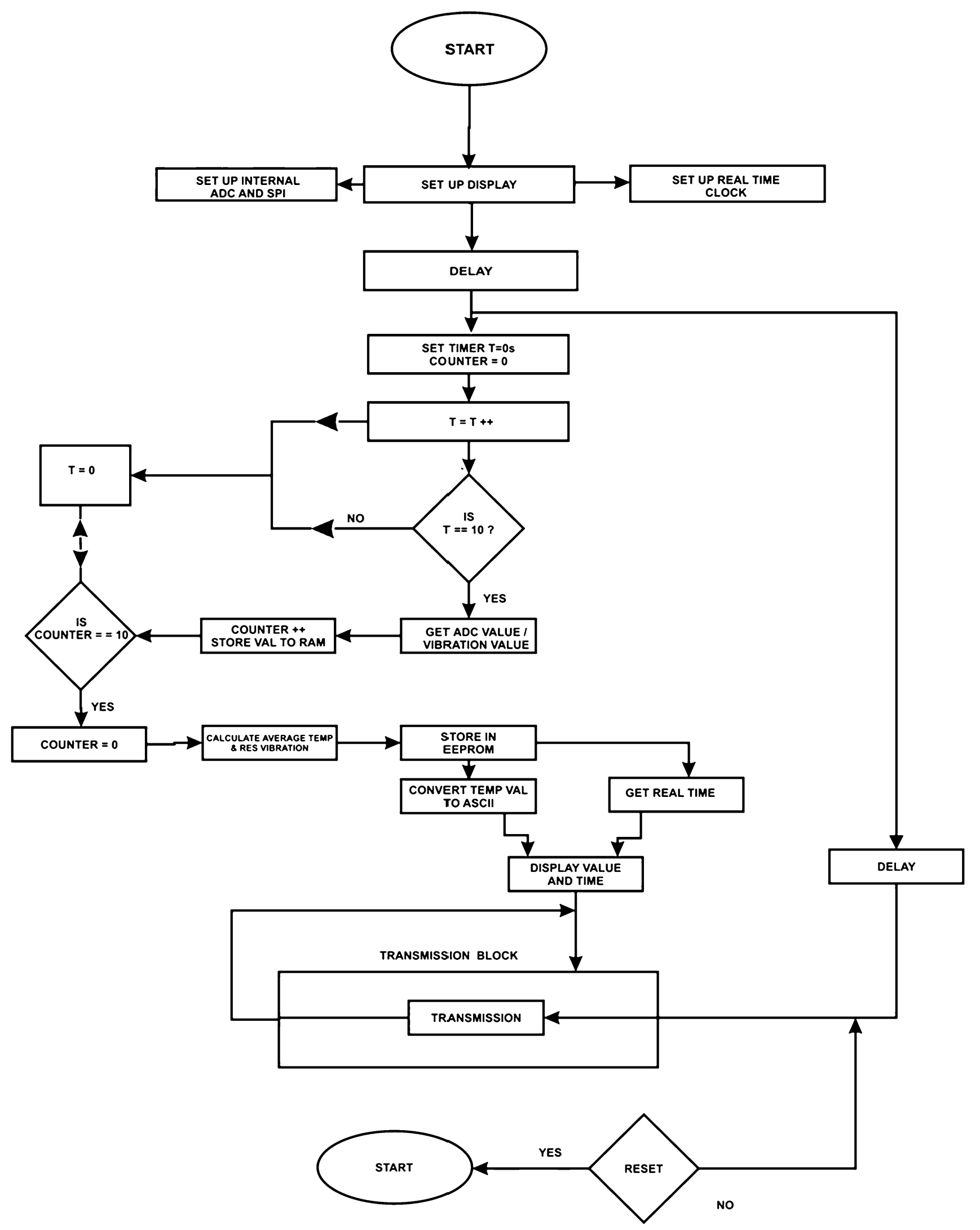

Fig. 3 Flowchart for workstation module 
Fig. 4 LCD customization for text display

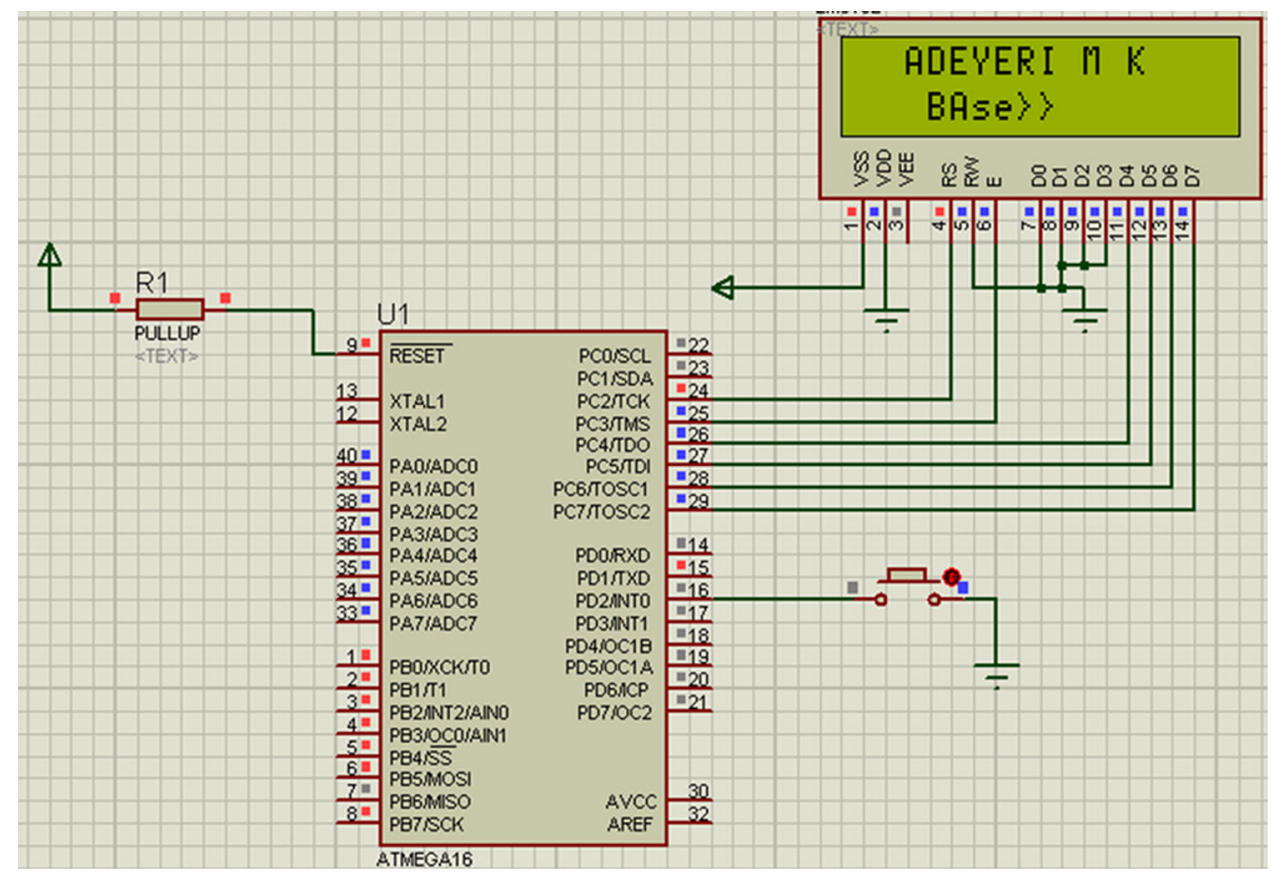

\section{Model flowchart}

The flowchart for implementing the vibration and temperature modeis as shown in Fig. 2.

The flowchart used in coding the temperature sensor and the vibration sensor so as to give room for the computer machine interface under the $\mathrm{C}$ language is as shown in Fig. 3.

\section{Development of hardware circuitry and interface to the microcontrollers}

As depicted in the block diagram of Fig. 1, at the centre of each of the monitoring hardware, there is a microcontroller interfaced to the sensors and other peripherals to enhance human interaction with the system.

According to the pictorial representation, the following hardware was interfaced to the monitoring system:

1. Liquid crystal display(LCD),

2. Real time clock (RTC), and

3. Transceiver.

These are as discussed as regards their operations.

\section{Base station circuitry}

Broadly speaking, the base station circuitry is divided into:

1. Serial port circuitry

The serial port circuitry handles the communication connection of the computer machines hardware interface of the base station with the computer system.
2. Wireless transceiver circuitry

Another important functionality added to this project is the ability of each monitoring system to be able to communicate with the base station system. In order to establish this, a wireless device was used. The wireless device used for this project is MRF24J40 Zigbee wireless transceiver. An internal transmit/receive (TR) switch combines the transmitter and receiver circuits into differential RFP and RFN pins. These pins are connected to impedance matching circuitry and antenna. An external power amplifier (PA) and could be controlled via the GPIO pins.

3. The display (LCD) circuitry.

The schematic of Fig. 4 shows the circuitry displayed when it was being simulated on PROTEUS Professional for circuit designs (NIC 2011).

\section{Workstation and base station circuitry design}

The workstation circuitry is divided into: temperature sensor circuitry, vibration sensor circuitry, real time clock circuitry, display circuitry, and wireless transceiver circuitry.

The workstation and base station circuitry is as shown in Fig. 5, while Fig. 6a-c shows how the workstation hardware was built.

The development of the hardware was carried out in the following sequence.

1. The schematics design of the hardware was done with the aid of look-up tables, data sheets of the various components being interfaced on Proteus ISIS software. 


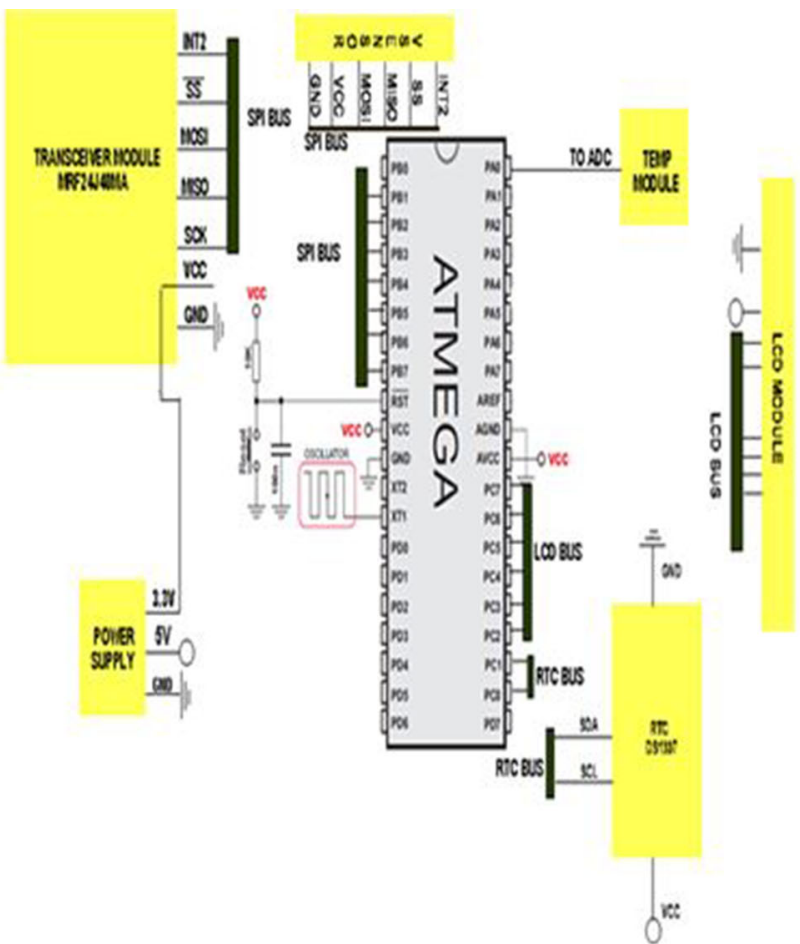

(a) Work Station Circuitry

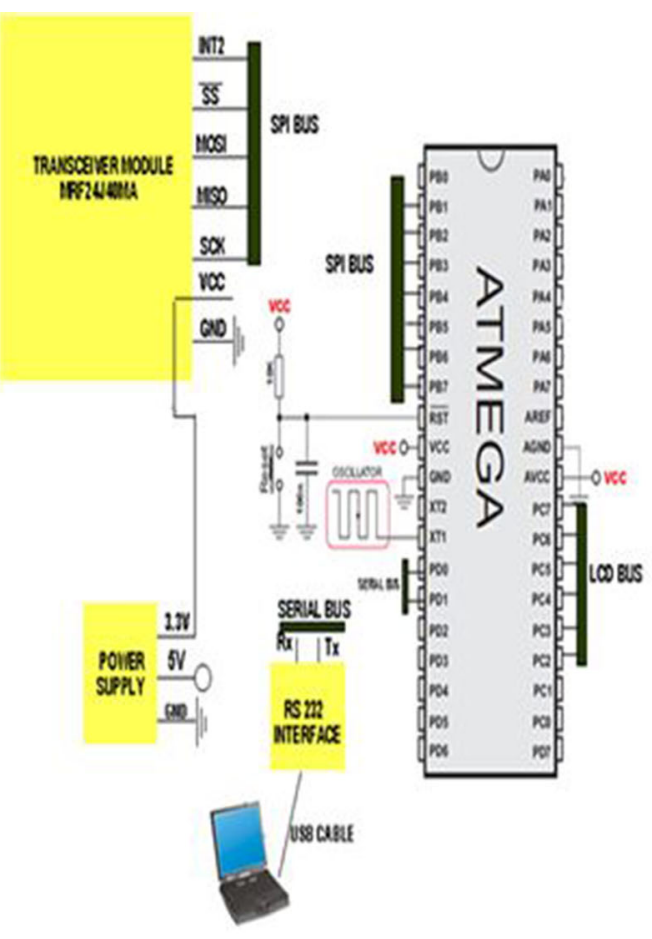

(b) Base Station Cicuitry

Fig. 5 Circuit diagram for the developed work station and base station

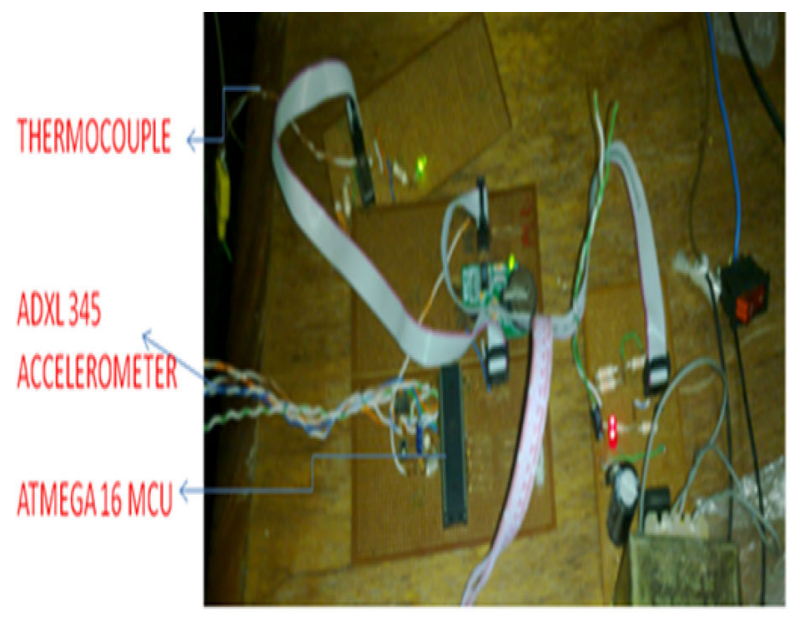

(a)

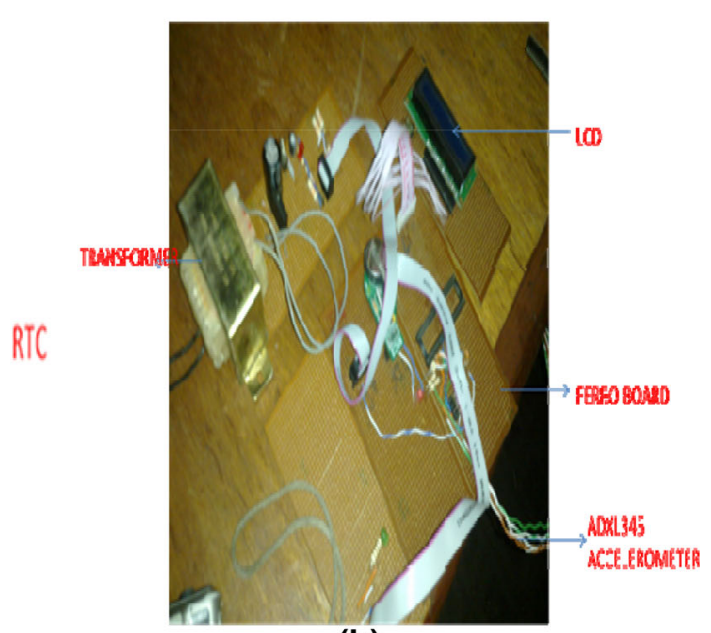

(b)

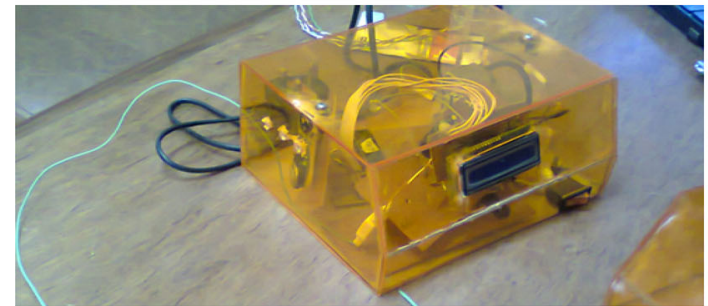

(c)

Fig. 6 Workstation hardware components on board at point of testing and the assembled hardware 
2. Each component was placed in position on the Vero board and held in connection using soldering leads and a hot soldering iron. This shows the implementation of the designed circuitry for the data acquisition system with some of the components soldered on the Vero board.

3. The embedded programming of ATMEGA32 microcontroller was done by interfacing it with a PC using a programming codes and the MikroC IDE. Program codes written in the $\mathrm{C}$ language were converted to their hexadecimal equivalent and written to the EEPROM memory of the microcontroller. The completed device is shown in Fig. 6. All components used were soldered on Vero board and a casing was built for them to give a protection of the device's circuitry.

\section{Hardware circuitry and interface to the microcontrollers of the base station}

As depicted in the block diagram of Fig. 5b, the monitoring systems are meant to sense the required conditioning parameters such as temperature and vibration, store the data and each transmits the stored data to the base station over wireless on request by the base station. The base station on the other hand, on receiving the data, transmits the data to the PC via serial port to a standalone windows software application developed to analyse the data and make necessary decisions to enhance maintenance of the machines and productivity. To enhance interactivity with this base station by the users, the following design provision is used:

1. Serial port communication between PC and Base station device, and

2. Graphical liquid crystal display (GLCD) interface.

\section{Power supply}

The entire system was powered by a central power supply, which is capable of providing 5, 3.3 and $3.0 \mathrm{~V}$. The design is composed of a voltage transformer, which steps down the $220 \mathrm{~V}$ supply to about $16 \mathrm{~V}$. The different sections of the system that need power supply get them from this central supply. The microcontroller for instance needs an absolute 5.0 V supply, the RTC needs 3.0 Volts and the ACCEL board needs $3.3 \mathrm{~V}$ and so on. These distributions were made through the effective use of ICU connectors of two by five and two by four jumpers.

\section{Calibration of hardware}

The calibration of the temperature thermocouple type $\mathrm{K}$ AD595 and the vibration ADXL345 sensors were calibrated based on their specification from their manufacturers (MickroElectronika).

\section{Temperature calibration}

To produce a temperature proportional output of $10 \mathrm{mV} /$ ${ }^{\circ} \mathrm{C}$, and provide an accurate reference junction over the rated operating temperature range, the AD595 is again trimmed at the factory to match the transfer characteristics of Type $\mathrm{K}$ thermocouple at $+25^{\circ} \mathrm{C}$. At this calibration temperature, the Seebeck coefficient, the rate of change of thermal voltage with respect to temperature at a given temperature is $0.44 \mu \mathrm{V} /{ }^{\circ} \mathrm{C}$ for a Type $\mathrm{K}$. This corresponds to a gain of 247.3 for the $\mathrm{AD} 595$ to realize a $10 \mathrm{mV} /{ }^{\circ} \mathrm{C}$ out-put. Although the device is trimmed for a $250 \mathrm{mV}$ output at $+25^{\circ} \mathrm{C}$, an input offset error is induced in the output amplifier resulting in offsets of $11 \mu \mathrm{V}$ for the AD595 (Joe 2011). To determine the actual output voltage from the AD595, the voltage output, $V_{\mathrm{o}}$ is therefore expressed as

$V_{\mathrm{o}}=\left(V_{\mathrm{k}}+11 \mu \mathrm{V}\right) \times 247.3$

where $V_{\mathrm{k}}$ is the type $\mathrm{K}$ voltage. And the corresponding temperature, $T^{\circ} \mathrm{C}$ would be

$T^{\mathrm{o}} \mathrm{C}=\frac{V_{\mathrm{o}}}{10 \mathrm{mV} /{ }^{\circ} \mathrm{C}}$

At $25^{\circ} \mathrm{C}, \quad V_{\mathrm{o}}=250 \mathrm{mV}$

and at $X^{\circ} \mathrm{C}, V_{\mathrm{o}}$ is $V_{\mathrm{o}}=V_{x} \mathrm{mV}$

where $V_{x}$ is the voltage read out at corresponding temperature of $X{ }^{\circ} \mathrm{C}$.

From Eqs. (7) and (9), it implies that change in temperature would be

$\Delta T=(X-25)^{\circ} \mathrm{C}$

and change in voltage be

$\Delta V=\left(V_{x}-250\right) \mathrm{mV}$

With reference from Eq. (7), change in temperature is therefore expressed as

$\Delta T{ }^{\circ} \mathrm{C}=\frac{\Delta V_{\mathrm{o}}}{10 \mathrm{mV} /{ }^{\circ} \mathrm{C}}$

Therefore,

$X-25=\frac{\Delta V}{10 \mathrm{mV} /{ }^{\circ} \mathrm{C}}$

Further simplification of Eq. (13) gives $X$ to be

$X=\left(\frac{\Delta V}{10 \mathrm{mV} /{ }^{\circ} \mathrm{C}}+25\right)$

when $\Delta V=V_{\mathrm{o}}-0.25$ 
Table 1 Vibration and temperature readings from extruder

\begin{tabular}{|c|c|c|c|c|c|c|c|c|}
\hline Time (min) & $\mathrm{V}(\mathrm{mm} / \mathrm{s})$ & $\mathrm{T}\left({ }^{\circ} \mathrm{C}\right)$ & Time $(\min )$ & $\mathrm{V}^{*}(\mathrm{~mm} / \mathrm{s})$ & $\mathrm{T}\left({ }^{\circ} \mathrm{C}\right)$ & Time (min) & $\mathrm{V}(\mathrm{mm} / \mathrm{s})$ & $\mathrm{T}\left({ }^{\circ} \mathrm{C}\right)$ \\
\hline 1 & 1.000 & 35.50 & 51 & 0.980 & 45.80 & 101 & 1.420 & 50.90 \\
\hline 2 & 1.000 & 35.52 & 52 & 1.100 & 45.90 & 102 & 1.440 & 51.00 \\
\hline 3 & 1.000 & 35.54 & 53 & 1.100 & 46.00 & 103 & 1.460 & 51.00 \\
\hline 4 & 1.010 & 35.56 & 54 & 1.100 & 46.10 & 104 & 1.480 & 51.00 \\
\hline 5 & 1.010 & 35.58 & 55 & 1.100 & 46.20 & 105 & 1.500 & 51.00 \\
\hline 6 & 1.010 & 35.60 & 56 & 1.100 & 46.30 & 106 & 1.520 & 51.00 \\
\hline 7 & 1.010 & 35.62 & 57 & 1.100 & 46.40 & 107 & 1.540 & 51.00 \\
\hline 8 & 1.010 & 36.02 & 58 & 1.100 & 46.50 & 108 & 1.560 & 51.00 \\
\hline 9 & 1.020 & 36.42 & 59 & 1.100 & 46.60 & 109 & 1.550 & 51.00 \\
\hline 10 & 1.020 & 36.82 & 60 & 1.100 & 46.70 & 110 & 1.540 & 51.00 \\
\hline 11 & 1.020 & 37.22 & 61 & 1.100 & 46.80 & 111 & 1.530 & 51.00 \\
\hline 12 & 1.020 & 37.62 & 62 & 1.100 & 46.90 & 112 & 1.520 & 51.00 \\
\hline 13 & 1.020 & 38.02 & 63 & 1.100 & 47.00 & 113 & 1.510 & 51.00 \\
\hline 14 & 1.030 & 38.42 & 64 & 1.100 & 47.10 & 114 & 1.500 & 51.00 \\
\hline 15 & 1.030 & 38.82 & 65 & 1.100 & 47.20 & 115 & 1.490 & 51.00 \\
\hline 16 & 1.030 & 39.22 & 66 & 1.100 & 47.30 & 116 & 1.480 & 51.00 \\
\hline 17 & 1.020 & 39.62 & 67 & 1.100 & 47.40 & 117 & 1.470 & 51.00 \\
\hline 18 & 1.020 & 40.02 & 68 & 1.100 & 47.50 & 118 & 1.460 & 51.00 \\
\hline 19 & 1.020 & 40.42 & 69 & 1.100 & 47.60 & 119 & 1.450 & 51.00 \\
\hline 20 & 1.010 & 40.82 & 70 & 1.100 & 47.70 & 120 & 1.440 & 51.00 \\
\hline 21 & 1.010 & 41.22 & 71 & 1.100 & 47.80 & 121 & 1.430 & 51.00 \\
\hline 22 & 1.010 & 41.62 & 72 & 1.100 & 47.90 & 122 & 1.420 & 51.00 \\
\hline 23 & 1.000 & 42.02 & 73 & 1.100 & 48.00 & 123 & 1.410 & 51.00 \\
\hline 24 & 1.000 & 42.42 & 74 & 1.100 & 48.10 & 124 & 1.400 & 51.00 \\
\hline 25 & 1.000 & 42.82 & 75 & 1.100 & 48.20 & 125 & 1.390 & 51.00 \\
\hline 26 & 1.000 & 43.22 & 76 & 1.100 & 48.30 & 126 & 1.380 & 51.00 \\
\hline 27 & 0.990 & 43.62 & 77 & 1.100 & 48.40 & 127 & 1.370 & 51.00 \\
\hline 28 & 0.990 & 44.02 & 78 & 1.100 & 48.50 & 128 & 1.360 & 51.00 \\
\hline 29 & 0.990 & 44.50 & 79 & 1.100 & 48.60 & 129 & 1.350 & 51.00 \\
\hline 30 & 0.980 & 44.50 & 80 & 1.100 & 48.70 & 130 & 1.340 & 51.00 \\
\hline 31 & 0.980 & 44.50 & 81 & 1.100 & 48.80 & 131 & 1.330 & 51.00 \\
\hline 32 & 0.980 & 44.50 & 82 & 1.100 & 48.90 & 132 & 1.320 & 51.00 \\
\hline 33 & 0.970 & 44.50 & 83 & 1.100 & 49.00 & 133 & 1.310 & 51.00 \\
\hline 34 & 0.970 & 44.50 & 84 & 1.100 & 49.10 & 134 & 1.300 & 51.00 \\
\hline 35 & 0.970 & 44.50 & 85 & 1.100 & 49.20 & 135 & 1.290 & 51.00 \\
\hline 36 & 0.970 & 44.50 & 86 & 1.100 & 49.30 & 136 & 1.280 & 51.00 \\
\hline 37 & 0.960 & 44.50 & 87 & 1.120 & 49.40 & 137 & 1.270 & 51.00 \\
\hline 38 & 0.960 & 44.50 & 88 & 1.140 & 49.50 & 138 & 1.260 & 51.00 \\
\hline 39 & 0.960 & 44.50 & 89 & 1.160 & 49.60 & 139 & 1.250 & 51.00 \\
\hline 40 & 0.950 & 44.60 & 90 & 1.180 & 49.70 & 140 & 1.240 & 51.00 \\
\hline 41 & 0.960 & 44.70 & 91 & 1.200 & 49.80 & 141 & 1.260 & 51.00 \\
\hline 42 & 0.960 & 44.80 & 92 & 1.220 & 49.90 & 142 & 1.280 & 51.00 \\
\hline 43 & 0.960 & 44.90 & 93 & 1.240 & 50.00 & 143 & 1.300 & 51.00 \\
\hline 44 & 0.960 & 45.00 & 94 & 1.260 & 50.10 & 144 & 1.320 & 51.00 \\
\hline 45 & 0.960 & 45.10 & 95 & 1.280 & 50.20 & 145 & 1.340 & 51.00 \\
\hline 46 & 0.970 & 45.20 & 96 & 1.300 & 50.30 & 146 & 1.360 & 51.00 \\
\hline 47 & 0.970 & 45.30 & 97 & 1.320 & 50.40 & 147 & 1.380 & 51.00 \\
\hline 48 & 0.970 & 45.40 & 98 & 1.340 & 50.50 & 148 & 1.400 & 51.00 \\
\hline 49 & 0.970 & 45.50 & 99 & 1.360 & 50.60 & 149 & 1.420 & 51.00 \\
\hline 50 & 0.970 & 45.60 & 100 & 1.380 & 50.70 & 150 & 1.440 & 51.00 \\
\hline
\end{tabular}

$V$ vibration, $T$ temperature 
Table 2 Correlation of time, vibration and temperature data

\begin{tabular}{llll}
\hline & Time of readings $(\mathrm{min})$ & Vibration value $(\mathrm{mm} / \mathrm{s})$ & Temp $\left({ }^{\circ} \mathrm{C}\right)$ \\
\hline Time of readings $(\mathrm{min})$ & 1 & & \\
Vibration value $(\mathrm{mm} / \mathrm{s})$ & 0.840634 & 1 & 1 \\
Temp $\left({ }^{\circ} \mathrm{C}\right)$ & 0.917332 & 0.746613 & 1 \\
\hline
\end{tabular}

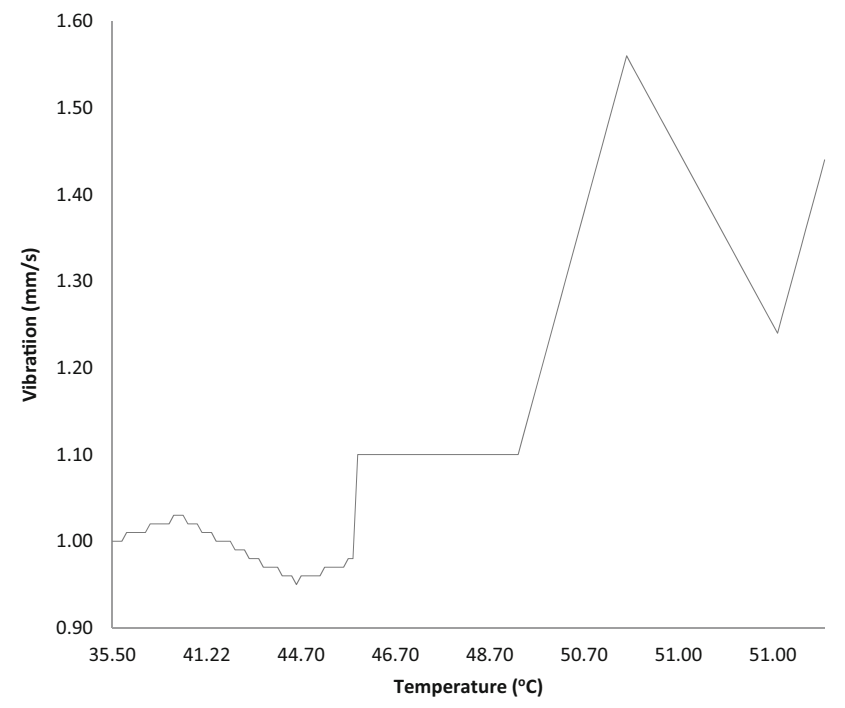

Fig. 7 Graph of vibration against temperature
$\Delta T=X-25$

and " $X{ }^{\circ} \mathrm{C}$ " which is the present read out value would be

$X=\Delta T+25$.

\section{Vibration calibration}

Accel SPI board of ADXL345 measures vibration in $x, y$ and $z$ axes. Adopting the principle of OTW (2009), the effective calibrated vibration $V_{b}$ was got from the expression of (Eq. 16). As

$V_{b}=\sqrt{x^{2}+y^{2}+z^{2}}$

The hardware was used in taking readings on their embedment into machines to see if the calibration is perfectly done. The readings obtained and the regression
Fig. 8 Curve fitting on vibration data for vibration model calibration

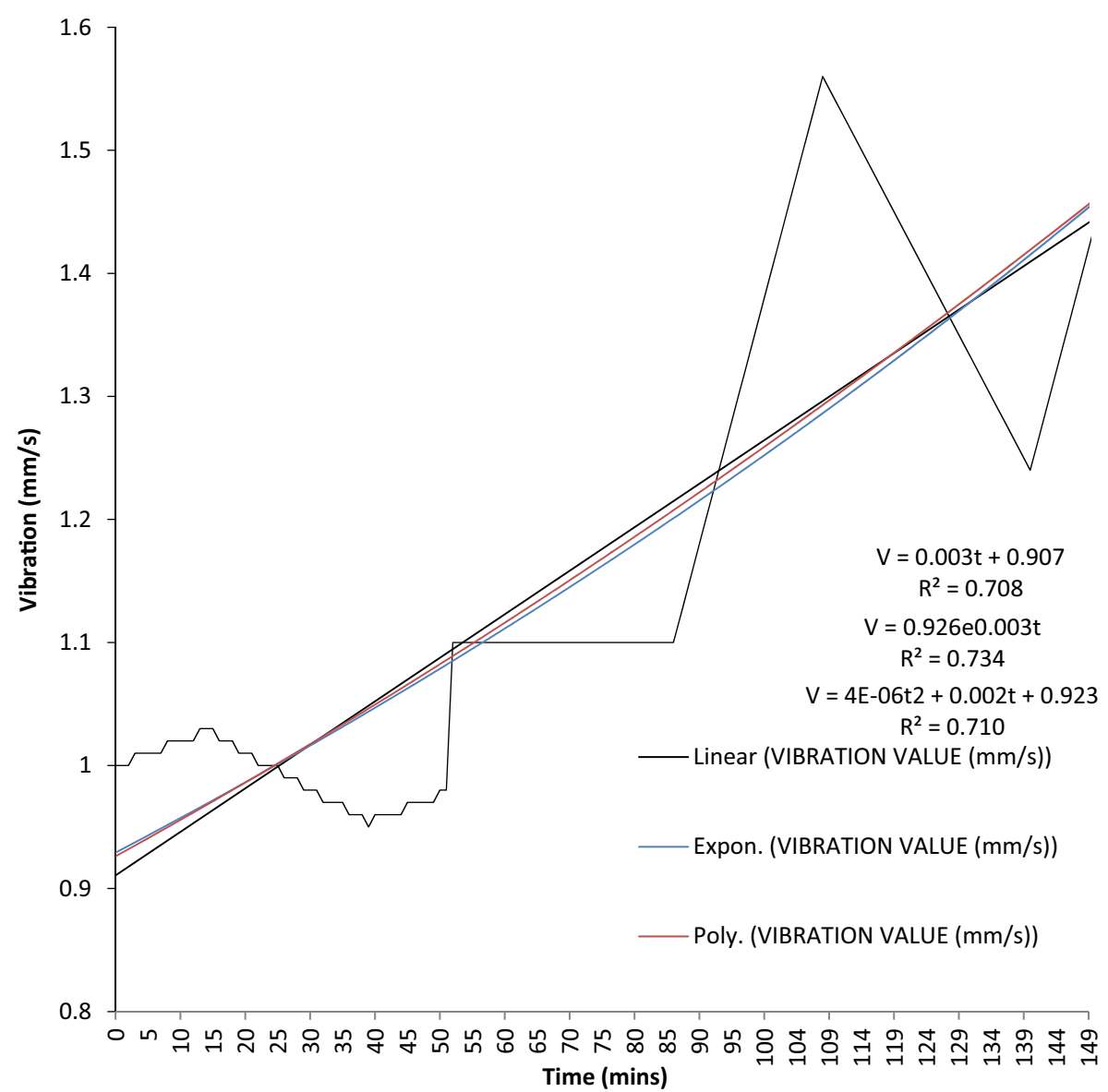


Fig. 9 Temperature data curve fitting for model calibration

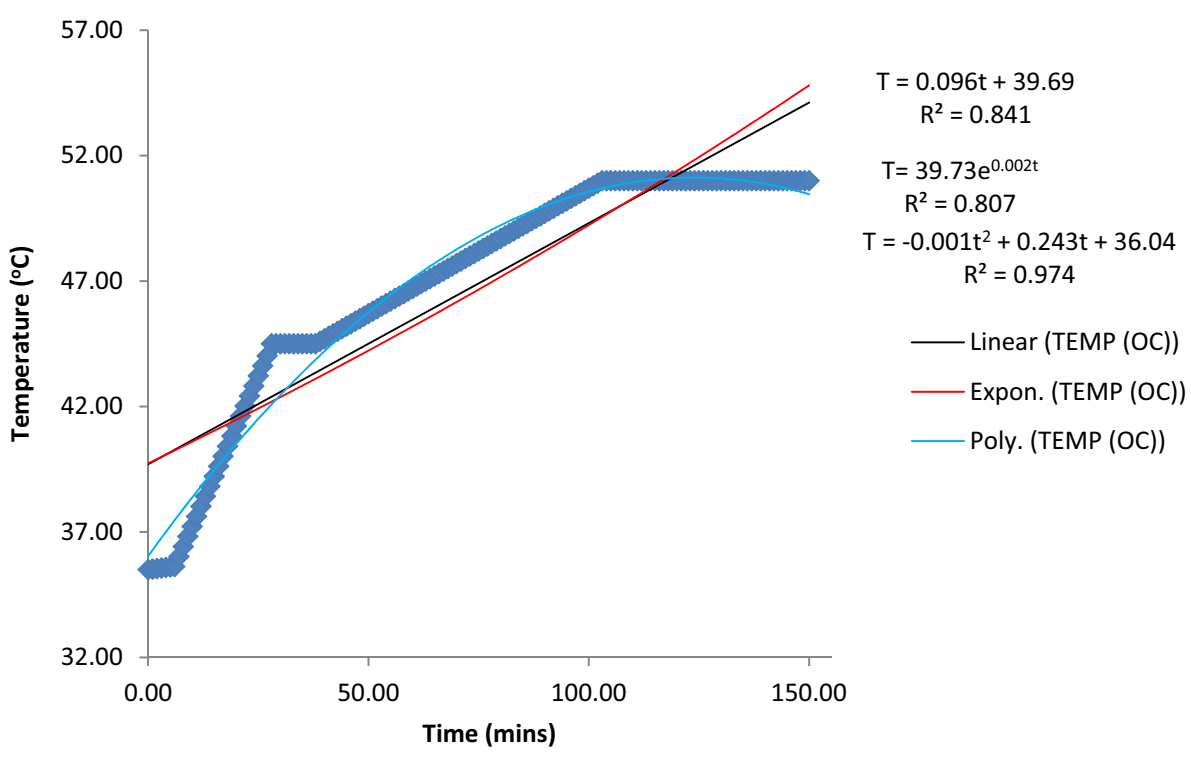

Table 3 Observed and predicted vibration data from gear box of extruder

\begin{tabular}{|c|c|c|c|c|c|c|c|c|}
\hline Time (min) & $\mathrm{OV}(\mathrm{mm} / \mathrm{s})$ & $\mathrm{PV}(\mathrm{mm} / \mathrm{s})$ & Time (min) & $\mathrm{OV}(\mathrm{mm} / \mathrm{s})$ & $\mathrm{PV}(\mathrm{mm} / \mathrm{s})$ & Time (min) & $\mathrm{OV}(\mathrm{mm} / \mathrm{s})$ & $\mathrm{PV}(\mathrm{mm} / \mathrm{s})$ \\
\hline 1 & 1.010 & 0.930 & 51 & 1.000 & 1.080 & 101 & 1.300 & 1.260 \\
\hline 2 & 1.010 & 0.930 & 52 & 1.000 & 1.080 & 102 & 1.300 & 1.260 \\
\hline 3 & 1.010 & 0.930 & 53 & 1.000 & 1.090 & 103 & 1.300 & 1.260 \\
\hline 4 & 1.010 & 0.940 & 54 & 1.100 & 1.090 & 104 & 1.300 & 1.270 \\
\hline 5 & 1.010 & 0.940 & 55 & 1.100 & 1.090 & 105 & 1.300 & 1.270 \\
\hline 6 & 1.010 & 0.940 & 56 & 1.100 & 1.100 & 106 & 1.300 & 1.280 \\
\hline 7 & 1.010 & 0.940 & 57 & 1.100 & 1.100 & 107 & 1.300 & 1.280 \\
\hline 8 & 1.000 & 0.950 & 58 & 1.100 & 1.100 & 108 & 1.220 & 1.280 \\
\hline 9 & 1.000 & 0.950 & 59 & 1.100 & 1.110 & 109 & 1.220 & 1.290 \\
\hline 10 & 1.000 & 0.950 & 60 & 1.100 & 1.110 & 110 & 1.220 & 1.290 \\
\hline 11 & 1.000 & 0.960 & 61 & 1.100 & 1.110 & 111 & 1.220 & 1.290 \\
\hline 12 & 1.000 & 0.960 & 62 & 1.100 & 1.120 & 112 & 1.220 & 1.300 \\
\hline 13 & 1.000 & 0.960 & 63 & 1.100 & 1.120 & 113 & 1.220 & 1.300 \\
\hline 14 & 1.000 & 0.960 & 64 & 1.100 & 1.120 & 114 & 1.220 & 1.310 \\
\hline 15 & 1.020 & 0.970 & 65 & 1.100 & 1.130 & 115 & 1.220 & 1.310 \\
\hline 16 & 1.020 & 0.970 & 66 & 1.100 & 1.130 & 116 & 1.290 & 1.310 \\
\hline 17 & 1.020 & 0.970 & 67 & 1.120 & 1.130 & 117 & 1.290 & 1.320 \\
\hline 18 & 1.020 & 0.980 & 68 & 1.140 & 1.140 & 118 & 1.290 & 1.320 \\
\hline 19 & 1.020 & 0.980 & 69 & 1.160 & 1.140 & 119 & 1.290 & 1.330 \\
\hline 20 & 1.020 & 0.980 & 70 & 1.180 & 1.140 & 120 & 1.290 & 1.330 \\
\hline 21 & 1.020 & 0.990 & 71 & 1.200 & 1.150 & 121 & 1.240 & 1.330 \\
\hline 22 & 1.020 & 0.990 & 72 & 1.120 & 1.150 & 122 & 1.240 & 1.340 \\
\hline 23 & 1.080 & 0.990 & 73 & 1.120 & 1.160 & 123 & 1.240 & 1.340 \\
\hline 24 & 1.080 & 0.990 & 74 & 1.120 & 1.160 & 124 & 1.240 & 1.350 \\
\hline 25 & 1.080 & 1.000 & 75 & 1.120 & 1.160 & 125 & 1.240 & 1.350 \\
\hline 26 & 1.080 & 1.000 & 76 & 1.120 & 1.170 & 126 & 1.240 & 1.350 \\
\hline 27 & 1.080 & 1.000 & 77 & 1.120 & 1.170 & 127 & 1.240 & 1.360 \\
\hline 28 & 1.080 & 1.010 & 78 & 1.120 & 1.170 & 128 & 1.280 & 1.360 \\
\hline 29 & 1.080 & 1.010 & 79 & 1.120 & 1.180 & 129 & 1.280 & 1.370 \\
\hline 30 & 1.080 & 1.010 & 80 & 1.120 & 1.180 & 130 & 1.280 & 1.370 \\
\hline
\end{tabular}


Table 3 continued

\begin{tabular}{|c|c|c|c|c|c|c|c|c|}
\hline Time (min) & $\mathrm{OV}(\mathrm{mm} / \mathrm{s})$ & $\mathrm{PV}(\mathrm{mm} / \mathrm{s})$ & Time (min) & $\mathrm{OV}(\mathrm{mm} / \mathrm{s})$ & $\mathrm{PV}(\mathrm{mm} / \mathrm{s})$ & Time (min) & $\mathrm{OV}(\mathrm{mm} / \mathrm{s})$ & $\mathrm{PV}(\mathrm{mm} / \mathrm{s})$ \\
\hline 31 & 1.080 & 1.020 & 81 & 1.120 & 1.180 & 131 & 1.280 & 1.370 \\
\hline 32 & 1.080 & 1.020 & 82 & 1.120 & 1.190 & 132 & 1.280 & 1.380 \\
\hline 33 & 1.080 & 1.020 & 83 & 1.120 & 1.190 & 133 & 1.280 & 1.380 \\
\hline 34 & 1.080 & 1.020 & 84 & 1.120 & 1.190 & 134 & 1.280 & 1.390 \\
\hline 35 & 1.080 & 1.030 & 85 & 1.120 & 1.200 & 135 & 1.280 & 1.390 \\
\hline 36 & 1.080 & 1.030 & 86 & 1.120 & 1.200 & 136 & 1.340 & 1.400 \\
\hline 37 & 1.080 & 1.030 & 87 & 1.200 & 1.200 & 137 & 1.340 & 1.400 \\
\hline 38 & 1.000 & 1.040 & 88 & 1.200 & 1.210 & 138 & 1.340 & 1.400 \\
\hline 39 & 1.000 & 1.040 & 89 & 1.200 & 1.210 & 139 & 1.340 & 1.410 \\
\hline 40 & 1.000 & 1.040 & 90 & 1.200 & 1.220 & 140 & 1.340 & 1.410 \\
\hline 41 & 1.000 & 1.050 & 91 & 1.200 & 1.220 & 141 & 1.340 & 1.420 \\
\hline 42 & 1.000 & 1.050 & 92 & 1.200 & 1.220 & 142 & 1.340 & 1.420 \\
\hline 43 & 1.000 & 1.050 & 93 & 1.200 & 1.230 & 143 & 1.340 & 1.430 \\
\hline 44 & 1.000 & 1.060 & 94 & 1.200 & 1.230 & 144 & 1.340 & 1.430 \\
\hline 45 & 1.000 & 1.060 & 95 & 1.200 & 1.230 & 145 & 1.340 & 1.430 \\
\hline 46 & 1.000 & 1.060 & 96 & 1.200 & 1.240 & 146 & 1.340 & 1.440 \\
\hline 47 & 1.000 & 1.070 & 97 & 1.200 & 1.240 & 147 & 1.260 & 1.440 \\
\hline 48 & 1.000 & 1.070 & 98 & 1.300 & 1.250 & 148 & 1.260 & 1.450 \\
\hline 49 & 1.000 & 1.070 & 99 & 1.300 & 1.250 & 149 & 1.260 & 1.450 \\
\hline 50 & 1.000 & 1.070 & 100 & 1.300 & 1.250 & 150 & 1.260 & 1.460 \\
\hline
\end{tabular}

$O V$ observed vibration values, $P V$ predicted vibration values

Table 4 Observed and predicted temperature data from electric motor of cutting machine

\begin{tabular}{|c|c|c|c|c|c|c|c|c|}
\hline Time (min) & $\mathrm{OT}\left({ }^{\circ} \mathrm{C}\right)$ & PT $\left({ }^{\circ} \mathrm{C}\right)$ & Time $(\min )$ & OT $\left({ }^{\circ} \mathrm{C}\right)$ & PT $\left({ }^{\circ} \mathrm{C}\right)$ & Time (min) & OT $\left({ }^{\circ} \mathrm{C}\right)$ & PT $\left({ }^{\circ} \mathrm{C}\right)$ \\
\hline 1 & 36.00 & 36.53 & 52 & 42.00 & 47.82 & 102 & 48.00 & 53.86 \\
\hline 2 & 36.00 & 36.80 & 53 & 43.00 & 47.99 & 103 & 48.00 & 53.93 \\
\hline 3 & 36.00 & 37.07 & 54 & 43.00 & 48.15 & 104 & 48.00 & 53.99 \\
\hline 4 & 36.00 & 37.34 & 55 & 43.00 & 48.32 & 105 & 48.00 & 54.06 \\
\hline 5 & 36.00 & 37.61 & 56 & 43.00 & 48.48 & 106 & 48.00 & 54.12 \\
\hline 6 & 36.00 & 37.87 & 57 & 43.00 & 48.65 & 107 & 48.00 & 54.19 \\
\hline 7 & 38.00 & 38.13 & 58 & 43.00 & 48.80 & 108 & 48.00 & 54.25 \\
\hline 8 & 38.00 & 38.39 & 59 & 43.00 & 48.96 & 109 & 49.00 & 54.30 \\
\hline 9 & 38.00 & 38.65 & 60 & 43.00 & 49.12 & 110 & 49.00 & 54.36 \\
\hline 10 & 38.00 & 38.90 & 61 & 43.00 & 49.27 & 111 & 49.00 & 54.41 \\
\hline 11 & 38.00 & 39.15 & 62 & 43.00 & 49.42 & 112 & 49.00 & 54.47 \\
\hline 12 & 38.00 & 39.40 & 63 & 43.00 & 49.57 & 113 & 49.00 & 54.52 \\
\hline 13 & 38.00 & 39.65 & 64 & 44.00 & 49.72 & 114 & 49.00 & 54.56 \\
\hline 14 & 39.00 & 39.90 & 65 & 44.00 & 49.87 & 115 & 49.00 & 54.61 \\
\hline 15 & 39.00 & 40.15 & 66 & 44.00 & 50.01 & 116 & 49.00 & 54.66 \\
\hline 16 & 39.00 & 40.39 & 67 & 44.00 & 50.15 & 117 & 49.00 & 54.70 \\
\hline 17 & 39.00 & 40.63 & 68 & 44.00 & 50.29 & 118 & 49.00 & 54.74 \\
\hline 18 & 39.00 & 40.87 & 69 & 44.00 & 50.43 & 119 & 49.00 & 54.78 \\
\hline 19 & 39.00 & 41.11 & 70 & 44.00 & 50.56 & 120 & 49.00 & 54.81 \\
\hline 20 & 39.00 & 41.34 & 71 & 44.00 & 50.70 & 121 & 50.00 & 54.85 \\
\hline 21 & 39.00 & 41.58 & 72 & 44.00 & 50.83 & 122 & 50.00 & 54.88 \\
\hline 22 & 39.00 & 41.81 & 73 & 44.00 & 50.96 & 123 & 50.00 & 54.91 \\
\hline 23 & 39.00 & 42.04 & 74 & 44.00 & 51.09 & 124 & 50.00 & 54.94 \\
\hline
\end{tabular}


Table 4 continued

\begin{tabular}{|c|c|c|c|c|c|c|c|c|}
\hline Time (min) & $\mathrm{OT}\left({ }^{\circ} \mathrm{C}\right)$ & $\mathrm{PT}\left({ }^{\circ} \mathrm{C}\right)$ & Time (min) & $\mathrm{OT}\left({ }^{\circ} \mathrm{C}\right)$ & $\mathrm{PT}\left({ }^{\circ} \mathrm{C}\right)$ & Time (min) & $\mathrm{OT}\left({ }^{\circ} \mathrm{C}\right)$ & PT $\left({ }^{\circ} \mathrm{C}\right)$ \\
\hline 24 & 40.00 & 42.26 & 75 & 44.00 & 51.21 & 125 & 50.00 & 54.96 \\
\hline 25 & 40.00 & 42.49 & 76 & 44.00 & 51.34 & 126 & 50.00 & 54.99 \\
\hline 26 & 40.00 & 42.71 & 77 & 45.00 & 51.46 & 127 & 50.00 & 55.01 \\
\hline 27 & 40.00 & 42.93 & 78 & 45.00 & 51.58 & 128 & 50.00 & 55.03 \\
\hline 28 & 40.00 & 43.15 & 79 & 45.00 & 51.70 & 129 & 50.00 & 55.05 \\
\hline 29 & 40.00 & 43.37 & 80 & 45.00 & 51.81 & 130 & 50.00 & 55.06 \\
\hline 30 & 40.00 & 43.58 & 81 & 45.00 & 51.93 & 131 & 50.00 & 55.08 \\
\hline 31 & 40.00 & 43.80 & 82 & 45.00 & 52.04 & 132 & 50.00 & 55.09 \\
\hline 32 & 40.00 & 44.01 & 83 & 46.80 & 52.15 & 133 & 50.00 & 55.10 \\
\hline 33 & 41.00 & 44.22 & 84 & 46.80 & 52.26 & 134 & 50.00 & 55.11 \\
\hline 34 & 41.00 & 44.43 & 85 & 46.80 & 52.36 & 135 & 50.00 & 55.12 \\
\hline 35 & 41.00 & 44.63 & 86 & 46.80 & 52.46 & 136 & 50.00 & 55.12 \\
\hline 36 & 41.00 & 44.83 & 87 & 46.80 & 52.57 & 137 & 50.00 & 55.12 \\
\hline 37 & 41.00 & 45.04 & 88 & 46.80 & 52.67 & 138 & 52.00 & 55.12 \\
\hline 38 & 41.00 & 45.24 & 89 & 46.80 & 52.76 & 139 & 52.00 & 55.12 \\
\hline 39 & 41.00 & 45.43 & 90 & 46.80 & 52.86 & 140 & 52.00 & 55.12 \\
\hline 40 & 41.00 & 45.63 & 91 & 46.80 & 52.95 & 141 & 52.00 & 55.11 \\
\hline 41 & 41.00 & 45.82 & 92 & 47.00 & 53.05 & 142 & 52.00 & 55.10 \\
\hline 42 & 42.00 & 46.01 & 93 & 47.00 & 53.14 & 143 & 52.00 & 55.10 \\
\hline 43 & 42.00 & 46.20 & 94 & 47.00 & 53.22 & 144 & 52.00 & 55.08 \\
\hline 44 & 42.00 & 46.39 & 95 & 47.00 & 53.31 & 145 & 52.00 & 55.07 \\
\hline 45 & 42.00 & 46.58 & 96 & 47.00 & 53.39 & 146 & 52.00 & 55.05 \\
\hline 46 & 42.00 & 46.76 & 97 & 47.00 & 53.48 & 147 & 52.00 & 55.04 \\
\hline 47 & 42.00 & 46.94 & 98 & 47.00 & 53.56 & 148 & 52.00 & 55.02 \\
\hline 48 & 42.00 & 47.12 & 99 & 47.00 & 53.63 & 149 & 52.00 & 55.00 \\
\hline 49 & 42.00 & 47.30 & 100 & 48.00 & 53.71 & 150 & 52.00 & 54.97 \\
\hline 50 & 42.00 & 47.47 & & & & & & \\
\hline
\end{tabular}

$O T$ observed temperature values, $P T$ predicted temperature values

analyses of curve fittings on them for verification of the calibration were fully discussed in subsequent section.

\section{Results and discussion}

A polyethylene bag production industry was used as case study for the implementation of the developed hardware. The key machines utilized are extruding machine, cutting, sealing and punching machines were the main machines in which the built hardware were used on.

\section{Data verification and analysis}

The temperature and vibration models developed were verified using some of the data collected from the machines by carrying out curve fitting on them.

Table 1 gives the extracted data of machines' vibration and temperature. A correlation test was performed to know if the parameters considered were related. The correlation result displayed in Table 2 shows that vibration tends to increase as time increases since the value of $R^{2}$ value is 0.841 which is almost 1 . Also temperature is correlated with time since the $R^{2}$ value is 0.917 .

Consequently, the $R^{2}$ value of 0.7466 arrived at gave the indication that there exit a correlation relationship between vibration and temperature. Plotting the values of these factors against each other, a nonlinear relationship was got as depicted on Fig. 7. However, the relationship is nonlinear, but there is indication that as vibration increases with time, temperature also increases.

The vibration verification was done using the developed hardware system to retrieve data from the polyethylene bag production machines. Some data were extracted from the retrieved data as seen in Table 2 . The verification principle adopted is the curve fitting/Goodness of fit approach. The data in Table 2 was plotted and the result is as shown in Fig. 8. From this figure, three curves fitting were done, namely; linear, exponential and polynomial, while Eqs. (17), (18) and (19), respectively, described their 


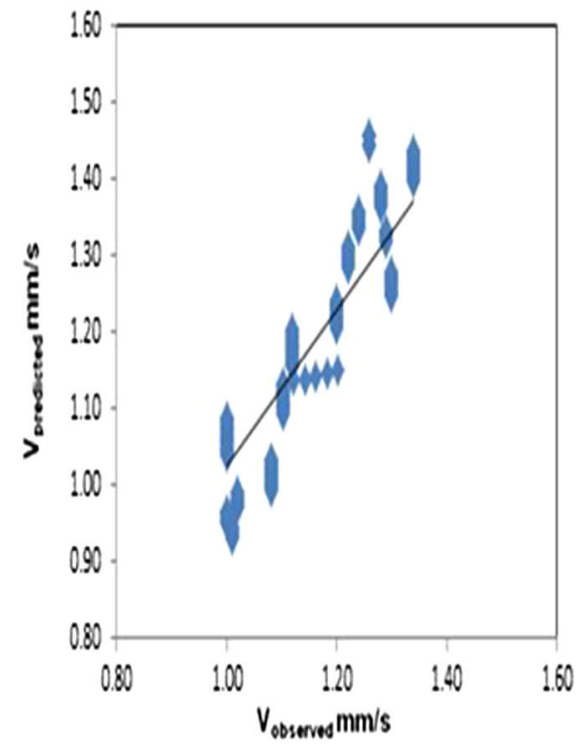

(a)

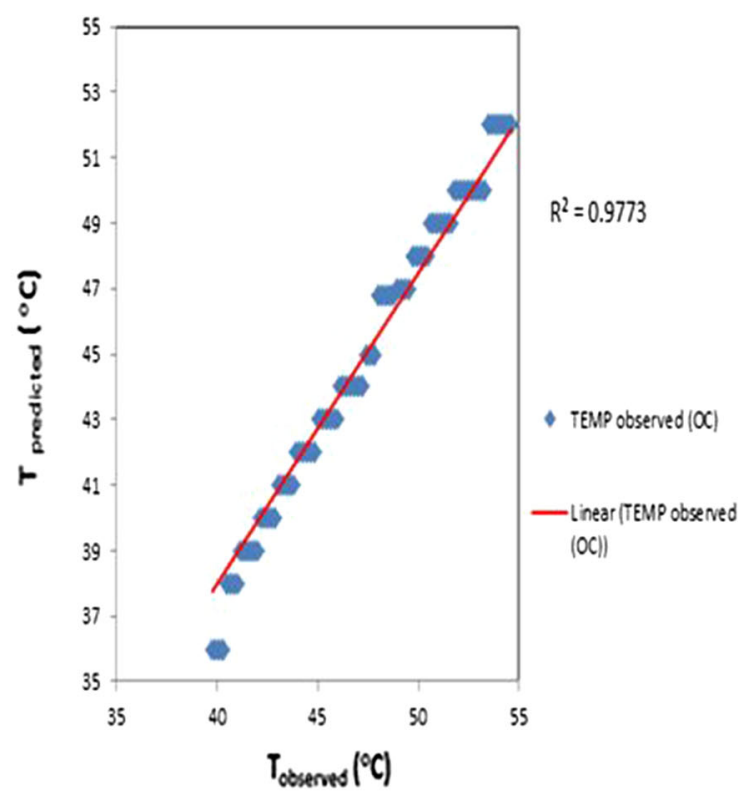

(b)

Fig. 10 a Graph of vibration model validation, $\mathbf{b}$ temperature model validation

mathematics formulation and their corresponding $R^{2}$ values.

$V=0.003 t+0.91$

and its $R^{2}=0.706$

$V=0.928 \ell^{0.003 t}$

and its $R^{2}=0.734$

$V=0.000004 t^{2}+0.002 t+0.925$

and its $R^{2}=0.708$

The exponential line or curve of best fit was picked based on the value of $R^{2}$, which is closest to value one (1) as compared to the other curves. This is a confirmation of the formulated vibration model of Eq. (4).

Similarly, the temperature calibration was done using the developed hardware system for both the substation and base-station to retrieve data from the polyethylene bag production machines. The temperature data in Table 2 was plotted and the result is as shown in Fig. 8. From this figure, three curves fitting were done, namely; linear, exponential and polynomial. The equations describing the various curves and their corresponding $R^{2}$ values are as stated in Eqs. (20), (21) and (22).

$T=0.096 t+39.69$

and its $R^{2}=0.841$

$T=39.73 \ell^{0.002 t}$

and its $R^{2}=0.807$

$T=-0.000 t^{2}+0.243 t+36.04$

and its $R^{2}=0.974$

Table 5 Anova analysis of the observed and predicted vibration data of gear box of extruder

\begin{tabular}{|c|c|c|c|c|c|c|}
\hline Groups & Count & & Sum & Average & & Variance \\
\hline \multicolumn{7}{|l|}{ Summary } \\
\hline Time (min) & 150 & & 11325 & 75.5 & & 1887.5 \\
\hline $\mathrm{OV}(\mathrm{mm} / \mathrm{s})$ & 150 & & 172.44 & 1.1496 & & 0.013026685 \\
\hline $\mathrm{PV}(\mathrm{mm} / \mathrm{s})$ & 150 & & 175.89 & 1.1726 & & 0.023730779 \\
\hline Source of variation & SS & $d f$ & MS & $F$ & $p$ value & $F$ crit \\
\hline \multicolumn{7}{|l|}{$A N O V A$} \\
\hline Between groups & 552627.245 & 2 & 276313.6 & \multirow[t]{3}{*}{439.1654172} & $3.2 \mathrm{E}-106$ & 3.015899 \\
\hline Within groups & 281242.9769 & 447 & 629.1789 & & & \\
\hline Total & 833870.2219 & 449 & & & & \\
\hline
\end{tabular}


Table 6 Anova analysis of the observed and predicted temperature data of electric motor of cutting machine

\begin{tabular}{|c|c|c|c|c|c|c|}
\hline Groups & Count & & Sum & Average & & Variance \\
\hline \multicolumn{7}{|l|}{ Summary } \\
\hline Time (min) & 148 & & 11,173 & 75.49324324 & & 1904.673423 \\
\hline OT $\left({ }^{\circ} \mathrm{C}\right)$ & 148 & & 6631.2 & 44.80540541 & & 20.99697739 \\
\hline PT $\left({ }^{\circ} \mathrm{C}\right)$ & 148 & & 7310.05 & 49.39222973 & & 31.99060928 \\
\hline Source of variation & SS & $d f$ & MS & $F$ & $p$ value & $F$ crit \\
\hline \multicolumn{7}{|l|}{$A N O V A$} \\
\hline Between groups & $81,106.23258$ & 2 & $40,553.11629$ & 62.14525816 & $1.67 \mathrm{E}-24$ & 3.016175 \\
\hline Within groups & $287,776.1685$ & 441 & 652.55367 & & & \\
\hline Total & $368,882.4011$ & 443 & & & & \\
\hline
\end{tabular}

The linear line or curve of best fit was picked because the value of $R^{2}$ of the linear curve is closer to one than that of the exponential curve. Also the equation of polynomial curve of second order is attesting to the fact that it should be linear as the coefficient of $t^{2}$ is -0.00 . And this supported the formulated temperature model of Eq. (3) (Fig. 9).

\section{Model validation}

The model equations developed were used to predict values for machines vibration and temperature. The observed readings from the hardware and the predicted values of the developed equations for vibration and temperature are as tabulated in Tables 3 and 4, respectively.

As depicted in Fig. 10a, the predicted vibration data were plotted against the observed values to determine the vibration model validity.

The $R$ value of 0.909 (which is almost $91 \%$ ) got from the plotted data as contained in Fig. 10a showed that the vibration model calibrated on the sensor is accurate to define the vibration behavior of the machine since it is closer to the value of one (1).

Also, Fig. 10b displayed the one-to-one plotting of the data in Table 4. The predicted temperature values were plotted against the observed values so as to determine the temperature model validity.

Consequently, using Tables 3 and 4 for the ANOVA analysis of the observed and predicted data, Tables 5 and 6 resulted therein.

The $R$ value of 0.988 (which is almost $99 \%$ ) got from the plotted data as contained in Fig. 10b showed that the temperature model calibration is accurate to define the temperature characteristics of the machine since it is closer to the value of one (1). Also, the ANOVA analysis of the vibration and temperature data observed and predicted shows that the respective $p$ values of $3.2 \times 10^{-106}$ and $1.67 \times 10^{-24}$ is an indication that the calibration of the hardware systems is highly significant.

\section{Conclusion}

This paper suggests a novel mechanism for machine condition monitoring of conventional machines using the developed hardware. The condition monitoring of production machines as means of monitoring machines' condition was achieved through the hardware developed for workstation and base station. The work-station hardware through the ADXL345 vibration sensor and type K thermocouple among other components embedded in it monitored the vibration and temperature of the machines, respectively. The behavioral patterns of the machines communicated to the base station hardware through a wireless transceiver were received from the computer system connected to the base station through universal serial bus port.

The paper established that there is correlation between time, vibration and temperature. As vibration increases with time, temperature also increases. Also, it has provided a platform of real time monitoring for conventional machines.

Due to lack of appropriate test equipment, it is recommended that further work should be done on work station hardware development that would accommodate the detection of fluid lubrication wear that occurs during operation and severe fatigue wear resulting from rolling contact fatigue in dry lubrication. Future work can be carried out by extending this approach to a system with multiple deterioration measures, and with multiple subsystems or multiple deterioration failure modes.

Acknowledgments TN Limited is highly appreciated for providing support in using their machines for testing the developed hardware system. Also, the Innovative Manufacturing and Design Solution Research Group, Department of Industrial Engineering, Tshwane University of Technology is held in high esteem.

Open Access This article is distributed under the terms of the Creative Commons Attribution 4.0 International License (http://crea tivecommons.org/licenses/by/4.0/), which permits unrestricted use, 
distribution, and reproduction in any medium, provided you give appropriate credit to the original author(s) and the source, provide a link to the Creative Commons license, and indicate if changes were made.

\section{References}

Adeyeri MK, Kareem B, Aderoba AA, Adewale OS (2012) Temperature based embedded programming algorithm for conventional machines condition monitoring proceedings of the fourth international conference on future computing technology, international academy, research and industrial association (IARIA), Nice-France, pp 51-57

Ahmad R, Kamaruddin S, Azid I, Almanar I (2011) Maintenance management decision model for preventive maintenance strategy on production equipment. J Ind Eng Int 7(13):22-34

Albino V, Carella G, Okogbaa O (1992) Maintenance polices in justin-time manufacturing lines. Int J Prod Res 30:369-382

Alsyouf I (2004) Cost effective maintenance for competitive advantages. Thesis for the degree of doctor of philosophy (terotechnology), School of Industrial Engineering, Växjö University, Sweden

Andijani A, Duffuaa S (2002) Critical evaluation of simulation studies in maintenance systems. Prod Plan Control 13(4):336-341

Ashraf WL (2004) A decision analysis model for maintenance policy selection using a CMMS. J Qual Maint Eng 10(3):191-202

Atmel (2010) 8-bit Microcontroller with $16 \mathrm{~K}$ bytes in-system programmable flash ATmega16. Atmel Incorporation, San Jose

Babaei H, Shahanaghi K, Bakhsha A (2011) A new approach for constraining failure probability of a critical deteriorating system Yard crane scheduling in port container terminals using genetic algorithm. J Ind Eng Int 7(12):52-59

Derigent W, Thomas E, Levrat E, Iung B (2009) Opportunistic maintenance based on fuzzy modelling of component proximity. CIRP Ann Manuf Technol 58:29-32

Duffuaa SO, Ben-Daya M, Al-Sultan KS, Andijani AA (2001) A generic conceptual simulation model for maintenance systems. J Qual Maint Eng 7(3):34-40

Greasly A (2005) Using system dynamics in a discrete-event simulation study of a manufacturing plant. Int $\mathrm{J}$ Oper Prod Manag 25(6):534-548

Grieb B (1992) Temperature measurement in process control. Advances in instrumentation and control, proceedings of the annual meeting of the instrument society of America, vol 47, Instrument Society of America, Research Triangle Park, North Carolina

Hausladen I, Bechheim C (2004) E-maintenance platform as a basis for business process integration. In: Proceedings of INDIN04, international conference on industrial informatics, pp 46-51

Iung B, Marquez CA (2006) Special issue on e-Maintenance. Comput Ind 57(6):473-606

Iung B, Levrat E, Marquez AC, Erbe H (2009) Conceptual framework for e-Maintenance: illustration by e-Maintenance technologies and platforms. Annu Rev Control 33(2009):220-229

Jardine AKS, Joseph T, Benjevic D (1999) Optimising conditionbased maintenance decisions for equipment subject to vibration monitoring. J Qual Maint Eng 5(3):192-202. (http://www. emerald-library.com). Retrieved: June, 2012

Jasper V, Warse K, Hans W (2011) Managing condition-based maintenance technology, a multiple case study in the process industry. J Qual Maint Engi 17 (1): 40-62. (http://www.emeraldlibrary.com. June, 2012)

Joe M (2011) Application note on thermocouple signal conditioning using the AD594/AD595. One Technology Way Norwood, USA. (http://www.analog.com. Accessed 26 Nov 2011)

Koc M, Lee J (2001) A system framework for next-generation e-Maintenance system. 2nd International symposium on environmentally conscious design and inverse manufacturing

Lee J, Scott LW (2006) Zero-breakdown machines and systems: productivity needs for next-generation maintenance. Eng Asset Manag 2006:31-43

Lee J, Ni J, Djurdjanovic D, Qiu H, Liao H (2006) Intelligent prognostic tools and e-maintenance. Comput Ind 57:476-489

Levrat E, Iung B, Marquez CA (2008) e-Maintenance: review and conceptual framework. Prod Plan Control 19(4):408-429

Lu S, Tu YC, Lu H (2007) Predictive condition-based maintenance for continuously deteriorating systems. Qual Reliab Eng Int 23:71-81. doi:10.1002/qre.823

Mahantesh N, Ramachandra A, Satosh Kumar AN (2008) Artificial intelligence-based condition monitoring for plant maintenance. Assem Autom 28(2):143-150

Marquez AC, Herguedas SA (2002) Models for maintenance optimization: a study for repairable systems and finite time periods. Reliab Eng Syst Saf 75(3):367-377

Marquez CA, Gupta JND, Herguedas SA (2003) Maintenance policies for a production system with constrained production rate and buffer capacity. Int J Prod Res 41(9):1909-1926

Muhammad AM, Sarmad N, Sepehr N (2011) The AVR microcontroller and embedded systems using assembly and C. Prentice Hall, London

Muller A, Suhner MC, Iung B (2008) Proactive maintenance for industrial system operation based on a formalised prognosis process. Reliab Eng Syst Saf 93(2):234-253

NIC-National Instruments Corporation (2011) Proteus software, National Instruments Corporation, Mopac Expwy Austin TX 78759-3504. http://www.ni.com/academic/circuits. Accessed 08 May 2011

Oladokun VO, Charles-Owaba OE, Nwaouzru CS (2006) An application of artificial neural network to maintenance management. J Ind Eng Int 2(3):19-26

OTW-One Technology Way (2009) “ADXL345 Data sheet”, analog devices, One Technology Way, USA. http://www.analog.com. Accessed 08 Oct 2011

Peng Y, Dong M, Zuo MJ (2010) Current status of machine prognostics in condition-based maintenance-a review. Int $\mathbf{J}$ Adv Manuf Technol 50:293-313

Tao B, Ding H, Xion YL (2003) IP sensor and its distributed networking application in e-Maintenance. In: Proceedings of the 2003 IEEE international conference on systems, man and cybernetics, vol 4, pp 3858-3863

Tsang A (2002) Strategic dimensions of maintenance management. JQME 8(1):7-39

Uca M, Qiu RG (2005) e-Maintenance in support of e-automated manufacturing systems. J Chin Inst Ind Eng 22(1):1-10

Voisin A, Levrat E, Cocheteux P, Iung B (2010) Generic prognosis model for proactive maintenance decision support: application to pre-industrial e-maintenance test. J Intell Manuf 21:177-193

Yuan J, Chaing J (2000) Optimal maintenance policy for a production system subject to aging and shocks. J Qual Maint Eng 6(3):200-216

Zineb S, Chadi S (2001) Maintenance integration in manufacturing systems: from the modeling tool to evaluation. Int J Flex Manuf Syst 13(3):267-285 